\title{
Meeting Report: Instituto Gulbenkian de Ciência- Institut Curie Young Scientists' Retreat 2019
}

Rion Brattig Correia ${ }^{1}$, Manon Josserand ${ }^{2}$, Diana V. Vieira ${ }^{1}$, Sara Andus ${ }^{2}$, Roberto Arbore ${ }^{1}$, Victoire Cachoux ${ }^{2}$, Maria Belén Carbonetto ${ }^{1}$, Inês Cristo ${ }^{2}$, Alba de Juan ${ }^{2}$, Satish Kailasam Mani ${ }^{2}$, Marta Marzullo ${ }^{1}$, Tânia Perestrelo ${ }^{1}$, Kyriel Pineaultt ${ }^{1}$, Dragan Stajic ${ }^{1}$.

${ }^{1}$ Instituto Gulbenkian de Ciência, Oeiras, Portugal

${ }^{2}$ Institut Curie, Paris, France

\begin{abstract}
This paper report presents the interdisciplinary science showcased at the Young Scientists Retreat 2019. The retreat was jointly organized by young researchers from Instituto Gulbenkian de Ciência (Portugal) and Institut Curie (France) and took place in Pedrógão Pequeno, a small village in the central region of Portugal in September 2019. Three keynote speakers were invited to present their work, Alfonso Martinez-Arias, Biola Javierre Martínez, and Sara Magalhães. In addition, accepted talks and posters from young researchers were presented the retreat. Talks were organized in sessions, which included: epigenetics and evolution, immunology, cell biology and metabolism, biostatistics and public health, biophysics, proliferation and morphogenesis, and cell polarity. A post-retreat survey, complied both by IGC attendees as well as a sample of nonattendees, discovered the existence of barriers that prevented the full participation of some junior scientists, especially female postdocs and postdocs with families. We discuss ways in which future retreats could help address this and additional issues common to young researchers in general.
\end{abstract}

Keywords: scientific meeting; interdisciplinary; meeting report; young researchers

\section{Introduction}

Crossing disciplinary borders has long been deemed central to solve some of the most vexing problems facing society. Large scientific achievements, from the Large Hadron Collider to the Human Genome Program, were only possible due to international, collaborative research agendas. Today, transdisciplinarity and international scientific networks are more important than ever, as society faces increased complex and intractable issues, from climate change and mass migrations to threats of mass pandemic. In the life sciences this trend is no different and can be seen in the diverse background of lab members within and across EU-LIFE institutes. Despite its importance, however, the capacity to cross scientific and national borders still meets with strong resistance (Ledford, 2015), from discipline-focused grant calls and panels to institutionalized walled-in domains. In order to instill in the next generation of scientists the importance of crossing borders, young scientists and researchers at the Instituto Gulbenkian de Ciência (IGC, Portugal) and Institut Curie (IC, France) joined forces to host the Young Scientists Retreat 2019, held between the $22^{\text {nd }}$ and $24^{\text {th }}$ of September 2019. The retreat took place at Hotel da Montanha in Pedrógão Pequeno, a charming small village in the central region of Portugal. 


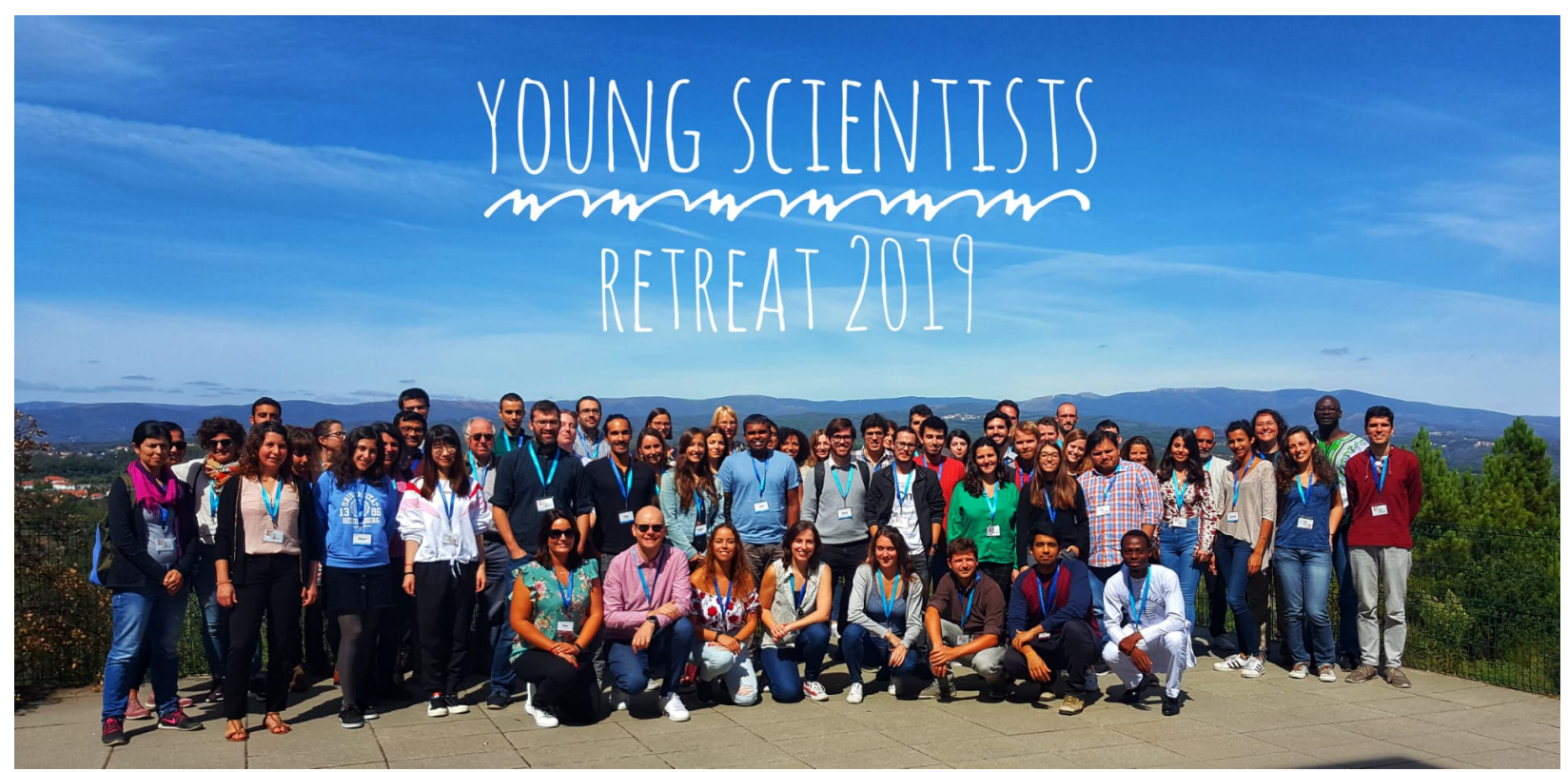

Figure 1 - Participants of the Young Scientists Retreat 2019.

The retreat was jointly organized by the IGC's postdoc committee and the IC's association of PhD students and postdocs. In total, we had 31 attendees from IGC and 27 from IC-in total, 58 young researchers who presented their work, either orally or during our two poster sessions. Importantly, not all presenters had complete stories and projects presented orally varied in their stage, with those in initial phases receiving constructive feedback from the present audience in the intended spirit of the retreat. Three keynote speakers, Alfonso Martinez-Arias, Biola Javierre Martínez, and Sara Magalhães, were invited to present not only their work, but also to talk about their career paths during the retreat. The retreat organizers deliberately selected keynotes at varying stages of their scientific career. Keynote speakers were invited to stay throughout the retreat and to participate in all of the activities, which fostered informal mentorship and career advice to young researchers. To further foster cross domain and institute networking, several social activities were organized, including a $3 \mathrm{~km}$ hike around the municipality, sponsored by Turismo da Sertã. The fresh air provided a break from scientific presentations, organized in sessions with varied topics, including: epigenetics and evolution, immunology, cell biology and metabolism, biostatistics and public health, biophysics, proliferation and morphogenesis, and cell polarity. Beyond the 14 selected researchers that presented their work orally during one of the 7 sessions, 39 researchers participated in one of the two poster sessions, which were organized by presenter affiliation to maximize cross-institute discussions. To demonstrate the breath of research presented at the retreat, next we discuss the keynote presentations and a selection of oral presentations from IGC and IC young researchers.

\section{Keynote I - Sara Magalhães}

Our scientific program started with a keynote presentation by Sara Magalhães, an ecological and evolutionary researcher from the Centre for Ecology, Evolution, and Environmental Changes $(\mathrm{cE} 3 \mathrm{c})$ at the Faculty of Science of the University of Lisbon. Magalhães is well known for her 
research with populations of mites and their interaction with microorganisms (Wolbachia) and plants (Zélé, 2018; Magalhães, 2007). A research agenda strongly grounded on theory. More than simply describe her previous and current work, Magalhães gave the young researchers audience a complete tour through her scientific career. After getting acquainted with the mites through videos, the audience had to imagine the mites being transported from Amsterdam where Magalhães did her PhD - to Montpellier, her first postdoctoral position. Importantly, Magalhães talk not only focused on her achievements towards becoming a successful scholar, but she also highlighted the hurdles and serendipitous moments that happened throughout her scientific path. As the present audience can attest, science often focuses on presenting completed work in a manner quite different from the meandering route that discovery in reality takes. Hence in the face of these so finalized "success stories", the scientific narrative often fails to highlight important difficulties and failures endured on the road to discovery, as well as the team work that enabled transformative science to be done. Magalhães' talk touched on these important realities and reminded us all that there are many paths towards becoming a successful scientist.

\section{Session I - Epigenetics and Evolution}

Our first young researcher talk was presented by Roberto Arbore, about the contribution of novel genes to the development of novel traits (Arbore, 2019). As Arbore explained, the co-option of preexisting developmental genes into new regulatory networks is an important and established mechanism by which evolutionary innovation is achieved. However, increasing evidence pinpoints a potential role for lineage-specific genes in the evolution of adaptive lineage-specific traits. In this ongoing work, Arbore uses wide-ranging functional analysis in the eco-evo-devo butterfly model Bicyclus anynana to assess the contribution of candidate lepidoptera-specific genes to the development of wind color patterns, an adaptive lepidoptera-specific trait used to deceive predators and in sexual selection.

Next, Dragan Stajic talked about epigenetic switching and how it outcompetes genetic mutation during adaptation to fluctuating stresses (Stajic, 2019). It is known that epigenetic inheritance allows for the emergence of phenotypic plasticity in clonal populations and it enables the rapid stochastic switching between distinct phenotypes. In any natural environment, where stress conditions can recurrently fluctuate, clones with an epigenetic control should be fitter than clones that just rely on classic genetic mutation. Using yeast as a model organism, Stajic tested this hypothesis and showed that epigenetic switching is advantageous under rapidly changing stresses.

\section{Session II - Immunology}

The immunology session also had two presenters. Zélia Gouveia presented her on-going project on controlling chimeric antigen receptor (CAR)-T cells potency using an intracellular transport switch. CAR-T cells are T-cells expressing CARs that are composed by an antibody-derived fragment (e.g., a single chain antibody variable fragment, scFc) fused to a transmembrane domain and co-stimulatory motifs required for its effector activity. Several scFv have been tested in clinical trials, with impressive outcomes for immunotherapy. In 2018, the first CAR-T therapy targeting CD19 tumor antigen was approved for the treatment of B-cell acute lymphoblastic 
leukemia. Gouveia is now adapting and testing a protein trafficking system to control the traffic of CAR molecules to the surface of T-cells to regulate therapeutic potency, an important step towards limiting CAR-T therapy side effects.

Next, Rafael Paiva talked about thymus autonomy (Paiva, 2019), or how T-cell development can be maintained independently of bone marrow input. He is using thymus transplantation experiments to identify a population of thymocytes that persist in the grafts, presumably maintaining T-cell development. His work proposes that a small population of thymocytes selfrenews and sustains thymus autonomy, thus unveiling the mechanisms involved in this process. The immunology session concluded the talks on the first day of the retreat. After a short break, participants resumed the first poster session, where IGC participants presented their work to IC scientists, which was followed by dinner and social activities.

\section{Keynote II - Biola Javierre Martínez}

The second day of the retreat restarted with a keynote lecture by Biola Javierre Martínez. Martinez is a molecular biologist and biochemist by training, working on 3D chromatin organization, hematopoiesis, and hematological malignancies at the Josep Carreras Leukaemia Research Institute in Barcelona. Javierre was recognized by the L'Oréal-UNESCO for Women in Science Programme. First, as the winner of the National award for Spain and then going on to be one of the 15 winners of the prestigious International Rising Talent Prizes in 2019. Her key scientific achievements include the design of new experimental and computational methods for studying chromatin organization, the novel description of promoter interactomes of human blood cell types and the pioneer interpretation of non-coding SNPs. The Javierre Group applies cutting edge experimental and bioinformatics approaches to understanding the specific 3D chromatin organization of haematopoietic cells and its alteration in blood cancers. In her talk, Javierre discussed her work on the 3D chromatin structure and its biological implications (Javierre et al., 2016, Burren, et al., 2017 \& Petersen et al., 2017), focusing on the promoter Hi-C capture technique that allowed a genome-wide identification of the promoter-interacting regions in human hematopoietic cells. Javierre's work connecting blood cancer alterations to putative target genes could help prioritize new disease candidate genes and metabolic pathways, while at the same time revealing insights into the genomic regulatory mechanisms underlying cancer. This work help us better predict outcomes and design improved and personalized treatment for cancer patients. Javierre's talk was inspirational to the whole audience but especially for female postdocs. Javierre has an active role in empowering more women to participate in science, develop great self-belief and to present their work more confidently, as she is also involved in the LIBRA Career Development Compass, a program that helps prepare ambitious female scientists for their next career step as independent researchers.

\section{Session III - Cell biology and Metabolism}

We restarted the talks with the cell biology and metabolism session. First, Miguel F. Pedro presented how specific eco-evolutionary contexts in the mouse gut reveal Escherichia coli metabolic versatility (Barroso-Batista and Pedro, 2019). They observed that in the absence of other members of the microbiota, E. coli adaptation to the mouse gut was very predictable and 
geared towards amino acid catabolism. However, when placed in a "two-partner" scenario, the presence of a single additional member of the microbiota (Blautia coccoides) altered the evolutionary trajectory in $E$. coli, causing a mutational profile as well as a nutrient composition more similar to what they had previously observed with a complex microbiota. Their results highlight the metabolic and evolutionary plasticity of $E$. coli, tailored to the specific ecology it experiences in the gut.

Next, Silvia Benito-Martinez presented her project on the characterization of the pigment organelle in keratinocytes. Human skin color rely on melanin pigments produced by melanocytes and transferred to epidermal keratinocytes. Benito-Martinez's work involves decrypting the molecular and cellular mechanisms underlying the entry, transport, and fate of melanin in skin keratinocytes. By developing an in vitro cell system recapitulating the in vivo behavior of melanin, her work aims to open new research avenues to design strategies modulating pigmentation in health or diseases.

The third and last talk of the cell biology and metabolism session was given by Temitope Wilson Ademolue on the neurometabolic control of energy homeostasis during infection (Ademolue, 2019). Infections lead to the development of sickness behavior, an evolutionary response that includes anorexia, which is characterized by the withdrawal of the infected host from food. If not countered by a host metabolic response that maintains the supply of metabolic substrates, anorexia of infection can lead to death of the host. Wilson's work showed that adipose tissue lipolysis is needed to maintain the supply of metabolic substrates during infection to support organismal metabolic homeostasis.

\section{Session IV - Biostatistics and Public Health}

After a short coffee break, we continued with three additional talks on our second day of retreat. Rion Brattig Correia showed how a complex systems approach to public health can uncover hidden biases in the occurrence of drug-drug interactions (DDI) (Brattig Correia, 2019). Their citywide analysis of electronic health records from Blumenau, a mid-size city in southern Brazil, indicated these DDI were prescribed to about $5 \%$ of the city population, with estimated hospitalization costs to be about $\$ 2$ per capita. Worryingly, women were at $60 \%$ increased risk of DDI when compared to men; $90 \%$ when only major DDI were considered. DDI risk also increases substantially with age with patients aged $70-79$ years having a $34 \%$ risk of DDI when they are dispensed two or more drugs concomitantly. Interestingly, a statistical null model demonstrates that age- and female-specific risk from increased polypharmacy fail by far to explain the observed DDI risk, suggesting unknown social or biological causes.

Next, Sandra Currás Alonso presented a spatial transcriptomics approach to study lung fibrogenesis (Currás-Alonso, 2019). The lung is a highly complex organ with at least 40 discrete cell types, with limited knowledge about their functional interaction in physiological and pathological conditions. The team implemented a droplet-based single cell RNAseq method to determine the molecular profile of mouse and human lung cells across different physiological and pathological states. The ultimate goal is to map the distinct lung cell types across different conditions and thus infer how the spatial organization evolves during fibrogenesis.

Before the coffee break, Temitope Akhigbe Etibor presented about influenza genome assembly (Alenquer, 2019). Influenza A virus (IAV) is a serious threat to human health, causing yearly 
epidemics. The IAV genome assembly is a selective process driven by RNA-RNA interactions and is hypothesized to lead to discrete punctate structures scattered throughout the cytosol. Contrary to the accepted view, the team showed that formation of structures precedes viral RNARNA interactions among distinct viral ribonucleoproteins (vRNPs).

\section{Session V - Biophysics}

After the coffee break Samuel Mathieu started the biophysics session, discussing the Golgi apparatus as a mechanosensitive organelle (Mathieu, 2019). The hypothesis currently being tested is that the Golgi apparatus could act as a mechanosensitive intracellular module, regulating membrane trafficking upon mechanical signals. Videos and schemes enhanced participants' understanding of the micromanipulation techniques being used to apply forces directly on Golgi membranes, or to the whole cell, with results suggesting that the Golgi apparatus indeed exhibits mechanosensitive properties.

Finally, closing the second day of talks, Venkata Ram Gannavarapu talked about the role of a protein complex in gut homeostasis. With an intuitive video demonstrating gut cells continued selfrenewing dynamics, Gannavarapu showed that this protein complex also has a critical role in the maintenance of apical junctional integrity and intestinal barrier function.

The Biophysics session concluded the talks on the second day. The second poster session followed with IC participants presenting their work to IGC scientists. Next, retreat participants enjoyed dinner which naturally transitioned into the official retreat party.

\section{Keynote III - Alfonso Martinez-Arias}

The keynote speaker on the third and last day of the retreat was Alfonso Martinez-Arias, a developmental biologist with training in biophysics and currently a professor of Developmental Mechanics at the University of Cambridge. Martinez-Arias have long pursued an interest in the logic of animal development, at understanding the principles that govern the development of organisms (Wolpert, 2015). However, the way at which Prof. Martinez-Arias has pursued this goal has shifted over time, as he explained to the audience at the retreat. Recently in his career, he has shifted from looking at development biology simply as an information processing problem to a framework more rooted in physical processes: "the processes we want to understand are dynamic and can be described as emergent properties from particular sets of elements". His talk focused on how ES cells self-organize to generate organs and tissue, using gastruloids as an in vitro model that mimics key aspects of embryogenesis to explore stochastic and deterministic processes in cell fate decisions. It was eye-opening, and perhaps heart-warming for the retreat attendees, when Prof. Martinez-Arias told them that this shift in his research to some degree undermined his previous work. It is not rare for postdocs to find that their recent results go against the established view of particular fields, or even, most worryingly, that their results counter previous results upon which they have based their starting careers.

\section{Session VI - Proliferation and Morphogenesis}

Following the keynote lecture, Markus Schliffka opened the proliferation and morphogenesis session talking about non-muscle myosin II heavy chain isoforms (Schliffka, 2019). During mouse 
pre-implantation development, actomyosin contractility shapes the blastocyst by powering cytokinesis and a series of morphogenetic movements. The specific roles of the distinct nonmuscle myosin heavy chain II (NMHC) isoforms during this phase are not well characterized. Using two knockouts (Myh9 \& Myh10), they find that Myh10 shows no phenotype when compared to wild-type, whereas Myh9 impacts cytokinesis and morphogenesis.

Next, Ojas Deshpande talked about astral microtubule crosslinking as a safeguard for efficient nuclear distribution during Drosophila syncytial development (Deshpande, 2019). Microtubules are indispensable in this process but we lack a mechanistic understanding of how the embryo achieves nuclear separation with its accurate periodicity. Using controlled cytoplasmic explants from Drosophila embryos, the authors suggest that astral microtubules associated with each nucleus play a key role. Furthermore, a knockdown of hypothesized candidate genes supports a mechanistic understanding of how nuclear distribution is achieved.

In the final talk of this session, Dureen Samandar Eweis discussed preliminary results on asymmetric division of the single cell embryo in nematodes (Eweis, 2019). Cell diversity arises from asymmetric cell divisions that differentially segregate fate determinants and lead to two daughter cells that are usually different in size. In C. elegans embryo this is a well-studied phenomena. In her PhD work, Eweis is characterizing these differences in two additional nematode species evolutionary distant from $C$. elegans. Preliminary results shows that these species have exaggerated shape changes prior to cleavage.

\section{Session VII - Cell Polarity}

Opening the last session of our retreat, Ana Milas presented her work on Drosophila oocyte polarization. Specifically at the seventh stage of oogenesis, posterior follicle cells (PFCs) signal to the oocyte leading to asymmetric localization of the partitioning defective (PAR) proteins, which ultimately define the first body axis (anterior-posterior). Using a mix of protein localization and laser ablation, her work was the first to show that PFCs are important to maintain PAR dependent polarization in the oocyte.

Next, Gehenna Guerrero-Serrano discussed the role of protein Rab6 in-vivo. Rab6 modulates the constitutive secretory pathway by controlling the release, motion and docking of secretory carriers with the plasma membrane. By generating gut-epithelium specific Rab6 knockout mice to analyze the effects of constitutive or inducible depletion of Rab6, they found epithelial disorganization and polarity defects during embryonic development and in the adult. The work suggests a role for Rab6 in polarity establishment during gut development, as well as epithelial cell adhesion and migration during gut homeostasis.

André Dias closed the last session of our retreat talking about primary and secondary body formation. The idea that trunk and tail formation follow different development strategies was proposed almost 100 years ago. However, the molecular mechanisms involved in the transition from primary to secondary are still mostly unknown. Dias presented mouse single-cell and twophoton live imaging data indicating that, during this transition, axial progenitor cells undergo a specialized type of epithelial to mesenchymal transition (EMT). In addition, through a series of gain and loss of function experiments, Dias showed that EMT in the tail bud is orchestrated by the combined activities of Alk5 signaling and the Snai1 transcription factor. 
This concluded the Cell Polarity session, which was followed by a few closing remarks from the retreat organizing committee. After lunch, participants sadly realized that the retreat had come to an end and it was time to return to their institutes. Back to Lisbon and Paris.

\section{Discussion and Lessons Learned}

We have provided through this report a glimpse into the interdisciplinary science presented at the Young Scientists Retreat 2019. The joint retreat between IGC and IC was a success, as measured by the post-retreat survey results - 93\% of IGC participants rated the venue and the retreat as either 'good' or 'excellent'. One of the most valuable aspects of the retreat was identified as the participants' talks, which directly speaks to the value of future interdisciplinary science and crossinstitute retreats within the EU-Life family, and beyond. Participants were excited to know what their peers were doing in the lab 'next door', or in another EU-Life institute. $75 \%$ of responders said they will attend a future cross-institute retreat. Furthermore, half of the attendees think we should have a cross-institute retreat every year and the other half believe every other year would be appropriate.

One of the issues that we identified from feedback from the meeting and the subsequent questionnaire, complied both by IGC attendees as well as a sample of non-attendees, was the existence of barriers that prevented the full participation of some junior scientists, especially female postdocs and postdocs with families. Amongst the responses cited for lack of participation, a lack of childcare provision at the meeting or other children-related difficulties, was an emergent theme, as was the fact that the retreat started on a weekend (Sunday). We also asked nonparticipants what would motivate them to attend forthcoming retreats. Among the answers received, we highlight the following: the inclusion of activities beyond science (e.g., non-scientific career talks, CV seminars, professionalization workshops, etc.), as well as hosting the retreat closer to home (e.g. 1 hour's driving distance), and having the retreat during workdays, were mentioned. We also believe these are shared reasons for the smaller number of postdoc attendees from IC, in comparison to PhD students. Historically ADIC-the association of PhD students and postdocs of Institut Curie-attracts more PhD students than postdocs.

The questionnaire also revealed that more female postdocs reported family difficulties in comparison to their male counterparts, as a reason for preventing them from attending the retreat. This is not a localized issue but rather, a problem recognized by the scientific community in general (Grogan, 2019). In addition, there were more male postdocs who submitted abstracts for talks. From the questionnaire we concluded that while male postdocs were more likely to submit abstracts that contained project plans or preliminary data, female postdocs only did so if they had a larger body of data. This emphasizes a gender-specific difference in the criteria that postdocs perceive to determine whether they should put themselves forward for a presentation. The postdoc committee at IGC and ADIC assume that this is a general phenomenon and are actively working to address these challenges in future retreats and more widely. Some drawbacks can possibly be overcome with changes in the next retreat organization, such as having the retreat during workdays; whereas others will possibly require additional institutional funding (or private sponsorship) to provide a better support for postdocs with children. Our postdoc committees are 
already actively working on measures to implement these recommendations in the next retreats organized at our institutes.

Beyond the issues that we note above, we believe such cross-institutional retreats are of immense value for young researchers. It provides not only a chance to know the science being done in another EU-Life institute, but to personally get to know the humans behind that science and the often-untold backstory behind many discoveries. International, collaborative research, such as those highlighted in the beginning of this report, spring from personal connections and a shared drive to solve increasingly complex and intractable problems. The organizers of the Young Scientists Retreat 2019 firmly believe that we have instilled in the participants this shared drive, as highlighted by a survey comment: "[..] the beauty of this retreat was in its small number as I was able to speak with everyone and have very enriching discussions. I loved it so much I almost felt nostalgic at the end of the retreat." We hope that EU-Life joint young scientist retreats become an annual feature of EU-Life activities.

\section{Author contributions}

R.B.C., M.J. and D.V.V. wrote the manuscript. All authors helped in the organization of the retreat. Correspondence should be addressed to postdoccommittee@igc.gulbenkian.pt or ysretreat18@gmail.com

\section{Acknowledgements}

We would like to thank the principal investigators Colin Adrain and Karina Xavier from Instituto Gulbenkian de Ciência for scientific guidance; Instituto Gulbenkian de Ciência, Institut Curie, The Company of Biologists, Labex DEEP, and Labex Celltisphybio for generous funding to the retreat; and the attendees of the retreat for lively presentations and discussions. We also would like to thank the staff of Hotel da Montanha for great hospitality, and João Antunes from Turismo da Sertã for the hiking activity around the municipality.

\section{References}

- Ledford, H (2015) Nature, 525, 308--311. doi:10.1038/525308a

- Zélé, F., Magalhães, S., Kéfi, S. et al. Ecology and evolution of facilitation among symbionts. Nat Commun 9, 4869 (2018) doi:10.1038/s41467-018-06779-w

- Magalhães, S., Forbes, M.R., Skoracka, A. et al. Exp Appl Acarol (2007) 42: 225. 10.1007/s10493-007-9091-0

- Javierre, B.M., Burren, O.S., Wilder, S.P. et al. Lineage-specific genome architecture links enhancers and non-coding disease variants to target gene promoters. Cell 167, 5 (2016). Doi: 10.1016/j.cell.2016.09.037

- Burren, O.S., García, A.R., Javierre, B.M. et al. Chromosome contacts in activated T cells identify autoimmune disease candidate genes. Genome Biology 18, 165 (2017). doi: 10.1186/s13059-017-1285-0 
- Petersen, R., Lambourne, J.J., Javierre, B.M. et al. Platelet function is modified by common sequence variation in megakaryocyte super enhancers. Nature Communications 8, 16058 (2017). doi: 10.1038/ncomms16058

- Beekman, R., Chapaprieta, V., Russiñol, N. et al. The reference epigenome and regulatory chromatin landscape of chronic lymphocytic leukemia. Nat Med 24, 868-880 (2018) doi:10.1038/s41591-018-0028-4

- Wolpert, L., Tickle, C., Arias, A.M. Principles of development. Oxford University Press, 2015.

- Arbore, R., Silva-Soares, N., Beldade, P. (2019) The contribution of novel genes to the development of novel traits. Talk presented at the Young Scientists Retreat 2019, Pedrógão Pequeno, Portugal.

- Stajic, D., Gordo, I. (2019) Epigenetic switching outcompetes genetic mutation during adaptation to fluctuating stresses. Talk presented at the Young Scientists Retreat 2019, Pedrógão Pequeno, Portugal.

- Gouveia, Z. (2019) Controlling CAR-T potency using an intracellular transport switch. Talk presented at the Young Scientists Retreat 2019, Pedrógão Pequeno, Portugal.

- Paiva, R. (2019) Thymus autonomy. Talk presented at the Young Scientists Retreat 2019, Pedrógão Pequeno, Portugal.

- Barroso-Batista, João and Pedro, Miguel Filipe and Sales-Dias, Joana and Pinto, Catarina Jesus Garcia and Pereira, Helena and Demengeot, Jocelyne and Gordo, Isabel and Xavier, Karina, Specific Eco-Evolutionary Contexts in the Mouse Gut Reveal Escherichia coli Metabolic Versatility (August 7, 2019). CURRENT-BIOLOGY-D-19-01278. Available at SSRN: https://ssrn.com/abstract=3433809 or http://dx.doi.org/10.2139/ssrn.3433809

- Benito-Martinez, S., Ilse, H., Maryse, R., Françoise, B., Christine, D., Graça, R. and Cédric, D. (2019) Characterization of the pigment organelle in Keratinocytes. Talk presented at the Young Scientists Retreat 2019, Pedrógão Pequeno, Portugal.

- Ademolue, T., Ramos, S., Mahu, I., Domingos, A., and Soares, M. (2019) Neurometabolic control of Energy Homeostasis during infection. Talk presented at the Young Scientists Retreat 2019, Pedrógão Pequeno, Portugal.

- Brattig Correia, R., de Araújo Kohler, L., Mattos, M.M. et al. City-wide electronic health records reveal gender and age biases in administration of known drug-drug interactions. npj Digit. Med. 2, 74 (2019) doi:10.1038/s41746-019-0141-x

- Currás-Alonso, S., Müeller, F., Walter, T., Seguin-Givelet, A., Lefevre, M., Jaillet, M., Mailleux, A., Girard, N., Crestani, B., Fouillade, C., Londoño-Vallejo, J.A. (2019) A spatial transcriptomics approach to study lung fibrogenesis. Talk presented at the Young Scientists Retreat 2019, Pedrógão Pequeno, Portugal.

- Alenquer, M., Vale-Costa, S., Etibor, T.A. et al. Influenza A virus ribonucleoproteins form liquid organelles at endoplasmic reticulum exit sites. Nat Commun 10, 1629 (2019) doi:10.1038/s41467-019-09549-4

- Mathieu, S., Goud, B., Sens, P., Manneville, J.B. (2019) The Golgi apparatus: a mechanosensitive organelle? Talk presented at the Young Scientists Retreat 2019, Pedrógão Pequeno, Portugal. 
- Schliffka, M.F., Tortorelli, A.F., Özgüç, O., de Plater, L., Maître, J.L. (2019) Non-muscle myosin II heavy chain isoforms in mouse preimplantation development. Talk presented at the Young Scientists Retreat 2019, Pedrógão Pequeno, Portugal.

- Deshpande , O., de-Carvalho, J., Vieira, D.V., Telley, I.A. (2019) Astral microtubule crosslinking by Feo safeguards uniform nuclear distribution in the Drosophila syncytium. bioRxiv 859975; Available from: https://doi.org/10.1101/859975.

- Eweis, D.S., Plastino, J. (2019) Asymmetric division of the single cell embryo in nematodes. Talk presented at the Young Scientists Retreat 2019, Pedrógão Pequeno, Portugal.

- Milas, A., de-Carvalho, J., Telley, I. (2019) Dissecting polarity formation in the Drosophila oocyte. Talk presented at the Young Scientists Retreat 2019, Pedrógão Pequeno, Portugal.

- Guerrero-Serrano G., Krndija D., Goud B., Vignjevic D. (2019) Rab6 in the gut homeostasis and Development. Talk presented at the Young Scientists Retreat 2019, Pedrógão Pequeno, Portugal.

- Dias, A., Lozovska, A., Wymeersch, F.J., Nóvoa, A., Binagui-Casas, A., Sobral, D., Martins, G.G., Wilson, V., Mallo, M. (2019) A TgfbRI/Snai1-dependent metastatic type EMT at the core of vertebrate axial elongation. Talk presented at the Young Scientists Retreat 2019, Pedrógão Pequeno, Portugal.

- Grogan, K.E. How the entire scientific community can confront gender bias in the workplace. Nat Ecol Evol 3, 3-6 (2019) doi:10.1038/s41559-018-0747-4 